\title{
Peningkatan Kinerja Keuangan dan Harga Saham melalui Pengungkapan Penerapan Good Corporate Governance (GCG) dan Ukuran Perusahaan pada BUMN Go Publik
}

\author{
Mailani Hamdani \\ Fakultas Ekonomi Universitas Terbuka \\ Tangerang Selatan \\ e-mail: mailani@ecampus.ut.ac.id \\ Gunoro Nupikso \\ Fakultas Ekonomi Universitas Terbuka \\ Tangerang Selatan
}

\begin{abstract}
The aims of this study were to analyze the effects of disclosures upon GCG implementation on the financial performance of listed state-owned enterprises (SOEs), the effect of the disclosure of GCG implementation on stock prices of listed SOEs, the effect of firm size on the financial performance of listed SOEs, and the effect of firm size on stock prices listed SOEs. The variables of this study were the Disclosures of GCG implementation measured by Minister of State for State-Owned Enterprises No. PER01 / MBU / 2011 regarding the implementation of GCG in SOEs, the sizes of companies which are reflected by total assets, financial performance reflected by the ROA and ROE, and the stock price reflected by stock returns. The results from this study were that the application of good corporate governance disclosures in annual reports was significantly related to the stock price. GCG implementation of significant disclosures was related to financial performance. Company size was significantly related to the stock price. And the size of the company was not significantly related to financial performance.
\end{abstract}

Keywords: Enterprise, Good Corporate Governance (GCG), Return stocks, ROA, ROE, Total Assets

\begin{abstract}
ABSTRAK
Tujuan dari penelitian ini adalah untuk menganalisis bagaimana pengaruh pengungkapan penerapann Good Corporate Governance (GCG) terhadap kinerja keuangan Badan Usaha Milik Negara (BUMN) Go Public, menganalisis pengaruh pengungkapan penerapan GCG terhadap harga saham BUMN Go Public, menganalisis pengaruh ukuran perusahaan terhadap kinerja keuangan BUMN Go Public, dan menganalisis pengaruh ukuran perusahaan terhadap harga saham BUMN Go Public. Variabel dari penelitian ini adalah Pengungkapan penerapan GCG yang diukur berdasarkan Peraturan Menteri Negara Badan Usaha Milik Negara Nomor: PER-01/MBU/2011 tentang penerapan GCG di BUMN, ukuran perusahaan yang direfleksikan oleh total aset, kinerja keuangan yang direfleksikan oleh Return On Assets (ROA) dan Return On Equity (ROE), serta harga saham yang direfleksikan oleh return saham. Hasil dari penelitian ini adalah Pengungkapan penerapan GCG didalam laporan tahunan berhubungan signifikan terhadap harga saham. Pengungkapan penerapan GCG berhubungan signifikan terhadap kinerja keuangan. Ukuran perusahaan berhubungan signifikan terhadap harga saham dan ukuran perusahaan tidak berhubungan signifikan terhadap kinerja keuangan.

Kata kunci: BUMN, Good Corporate Governance (GCG), Return saham, ROA, ROE, Total Aset
\end{abstract}




\section{Pendahuluan}

Pada Mei 2014, jumlah BUMN yang berada di Kementerian BUMN adalah sebanyak 138 BUMN dengan pertumbuhan laba dari tahun 1992-2013 sebesar 36,75\%. Guna mengoptimalkan peran Badan Usaha Milik Negara, pengurusan dan pengawasannya harus dilakukan secara profesional, maka terbitlah Undang-undang No.19 Tahun 2003 tentang Badan Usaha Milik Negara (BUMN).

Berdasarkan penjelasan UU No.19 Tahun 2003 Pasal 5 dan 6 dapat ditarik kesimpulan bahwa pengelolaan suatu BUMN haruslah dilaksanakan sesuai dengan prinsip Good Corporate Governance. Hal ini diperkuat dengan adanya Peraturan Menteri Negara BUMN nomor PER-01/MBU/2011 tentang Penerapan Tata Kelola yang baik, hal ini mengharuskan setiap Badan Usaha Milik Negara menerapkan tata kelola yang baik atau good corporate governance.

Good Corporate Governance menurut Peraturan Menteri Negara BUMN nomor PER-01/MBU/2011 adalah prinsip-prinsip yang mendasari suatu proses dan mekanisme pengelolaan perusahaan berlandaskan peraturan perundang-undangan dan etika berusaha. Penerapan Good Corporate Governance sangat penting karena dapat membantu dalam pengambilan keputusan yang baik dalam pengelolaan perusahaan sehingga dapat meningkatkan nilai perusahaan agar dapat bersaing dengan bebas.

Tujuan penerapan prinsip-prinsip GCG bagi BUMN adalah mengoptimalkan nilai BUMN agar perusahaan memiliki daya saing yang kuat, baik secara nasional maupun internasional, sehingga mampu mempertahankan keberadaannya dan hidup berkelanjutan untuk mencapai maksud dan tujuan BUMN; mendorong pengelolaan BUMN secara profesional, efisien, dan efektif, serta memberdayakan fungsi dan meningkatkan kemandirian Organ Persero/Organ Perum; mendorong agar Organ Persero/Organ Perum dalam membuat keputusan dan menjalankan tindakan dilandasi nilai moral yang tinggi dan kepatuhan terhadap peraturan perundang-undangan, serta kesadaran akan adanya tanggung jawab sosial BUMN terhadap pemangku kepentingan maupun kelestarian lingkungan di sekitar BUMN; meningkatkan kontribusi BUMN dalam perekonomian nasional dan meningkatkan iklim yang kondusif bagi perkembangan investasi nasional. Penerapan GCG dapat dilihat dari laporan pengungkapan GCG yang biasanya tersaji dalam laporan tahunan BUMN atau laporan tersendiri terpisah dari laporan tahunan.

Selain pengelolaannya yang harus berdasarkan prinsip-prinsip good corporate governance, keberhasilan BUMN dalam menjalankan usahanya dapat dilihat dari kinerja keuangannya dan harga saham. Penilaian atas kinerja keuangan BUMN dapat dilihat dari laporan keuangan BUMN tersebut. Laporan keuangan merupakan datadata yang berisikan tentang informasi kinerja perusahaan terutama kondisi keuangan perusahaan. Laporan keuangan ini disajikan oleh perusahaan sebagai salah satu bentuk transparansi. Dengan adanya laporan keuangan ini, diharapkan dapat membantu semua pihak yang berkepentingan dapat mengambil keputusan dengan tepat.

Tentang pentingnya mekanisme corporate governance, banyak penelitian yang meneliti hubungan corporate governance tersebut. Mengingat keuntungan yang akan didapat oleh shareholder dan makin baiknya performance perusahaan itu sendiri, maka penerapan good corporate governance terhadap kinerja keuangan dan harga saham, harus dilakukan. Seperti penelitian yang dilakukan oleh Lastanti (2004), 
menyatakan bahwa terdapat hubungan struktur corporate governance dengan kinerja perusahaan dan reaksi pasar. Pendapat ini didukung oleh Prasinta (2012) yang menyatakan bahwa implementasi good corporate governance berpengaruh terhadap kinerja operasional, namun pencapaian laba perusahaan dan respon pasar atas implementasi good corporate governance masih kurang.

Bersadarkan penelitian-penelitian terdahulu, maka tujuan dari penelitian ini adalah untuk menganalisis bagaimana pengaruh pengungkapan penerapan Good Corporate Governance terhadap kinerja keuangan BUMN go public, menganalisis pengaruh pengungkapan penerapan Good Corporate Governance terhadap harga saham BUMN go public, menganalisis pengaruh ukuran perusahaan terhadap kinerja keuangan BUMN go public, dan menganalisis pengaruh ukuran perusahaan terhadap harga saham BUMN go public.

\section{Metode Penelitian}

Jenis penelitian ini termasuk penelitian kuantitatif dengan periode pengamatan dari tahun 2010-2014. Populasi dalam penelitian ini adalah perusahaan BUMN yang terdaftar di Bursa Efek Indonesia yang mempublikasikan laporan tahunan. Pemilihan Sampel penelitian didasarkan dengan metode purposive sampling yang berarti pemilihan sampel berdasarkan kriteria tertentu.

Untuk membantu pengolahan dan analisis data, digunakan bantuan komputer yang menggunakan alat statistik, yaitu sofware microsoft Excel dan smartPLS. Variabel yang digunakan dalam penelitian ini adalah :

Tabel 1. Variabel penelitian

\begin{tabular}{lll}
\hline No Variabel Laten & Variabel Indikator & \multicolumn{1}{c}{ Defenisi Operasional Variabel } \\
\hline & Pemegang saham & Pengungkapan penerapan GCG diukur dengan \\
& Dewan komisaris & berdasarkan kriteria yang ditetapkan di dalam \\
& Direksi & Peraturan Menteri Negara Badan Usaha Milik \\
& Auditor eksternal & Negara Nomor: PER-01/MBU/2011. Pendekatan \\
& Informasi & untuk menghitung pengungkapan GCG yang \\
& Keselamatan dan & digunakan yaitu pendekatan dikotomi. Setiap \\
& kesempatan kerja & item GCG dalam instrumen penelitian diberi \\
& Pelestarian & nilai 1 jika perusahaan mengungkapkan item \\
& lingkungan & tersebut dalam laporan tahunan dan diberi nilai \\
& Hubungan dengan & 0 jika perusahaan tidak mengungkapkan. \\
& Pemangku & \\
& kepentingan & \\
& (stakeholders) & \\
& Etika berusaha, anti & \\
& korupsi dan donasi & \\
& Program pengenalan \\
& BUMN \\
& Pengukuran terhadap \\
& penerapan GCG
\end{tabular}


Lanjutan Tabel 1.

\begin{tabular}{|c|c|c|c|}
\hline No & Variabel Laten & Variabel Indikator & Defenisi Operasional Variabel \\
\hline 2 & $\begin{array}{l}\text { Ukuran Perusahaan } \\
\text { (Kasmir 2011) }\end{array}$ & Total Aset & $\begin{array}{l}\text { Adalah ukuran perusahaan yang diproksikan } \\
\text { dengan total asset }\end{array}$ \\
\hline \multirow{6}{*}{3} & \multirow{6}{*}{$\begin{array}{l}\text { Kinerja keuangan } \\
\text { perusahaan } \\
\text { (Kasmir 2011) }\end{array}$} & \multirow[t]{3}{*}{ ROA } & $\begin{array}{l}\text { Adalah rasio yang menunjukkan hasil atas } \\
\text { jumlah aktiva yang digunakan dalam } \\
\text { perusahaan, dengan rumus : }\end{array}$ \\
\hline & & & Return onAssets $(\mathrm{ROA})=$ EarningAfter $\operatorname{Tax}(\mathrm{EAT})$ \\
\hline & & & Keturnonassets $($ NOA $)=\frac{\text { Total Aktiva }}{}$ \\
\hline & & \multirow{3}{*}{ ROE } & $\begin{array}{l}\text { Adalah rasio untuk mengukur laba bersih } \\
\text { sesudah pajak dengan modal sendiri, dengan }\end{array}$ \\
\hline & & & rumus : \\
\hline & & & Return On Equity $(\mathrm{ROE})=\frac{\text { Earning After Interest and Tax }}{\text { Equity }}$ \\
\hline \multirow[t]{2}{*}{4} & \multirow[t]{2}{*}{$\begin{array}{l}\text { Harga saham } \\
\text { (Jogiyanto 2003) }\end{array}$} & \multirow[t]{2}{*}{ Return saham } & $\begin{array}{l}\text { Data harga saham yang digunakan yaitu data } \\
\text { harga saham pada hari kesepuluh sebelum dan } \\
\text { setelah publikasi laporan keuangan. Dengan } \\
\text { rumus sebagai berikut: }\end{array}$ \\
\hline & & & Return saham $\left(R_{i}\right)=\frac{P_{t}-P_{t-1}}{P_{t-1}}$ \\
\hline
\end{tabular}

\section{Hasil dan Pembahasan}

\section{III.1. Menilai Outer Model}

Dari langkah-langkah penggunaan freeware SmartPLS 2.0 yang ada, maka langkah pertama adalah menilai tiga kriteria didalam penggunaan teknik analisa data yaitu menilai outer model melalui Convergent Validity, Discriminant Validity dan Composite Reability (Yamin dan Kurniawan 2009; 2011).

\section{Convergent Validity}

Convergent validity dari model pengukuran dengan refleksif indikator dinilai berdasarkan korelasi antara item score/component score yang diestimasi dengan software PLS. Dalam penelitian ini digunakan batas loading factor sebesar 0,40. Nilai loading factor yang bernilai di atas 0,4 menunjukkan bahwa indikator-indikator memiliki kekuatan interelasi dalam merefleksikan konstruk. Dari hasil analisa dengan menjalankan calculate-PLS algorithm, diperoleh hasil seperti pada Gambar 1. 


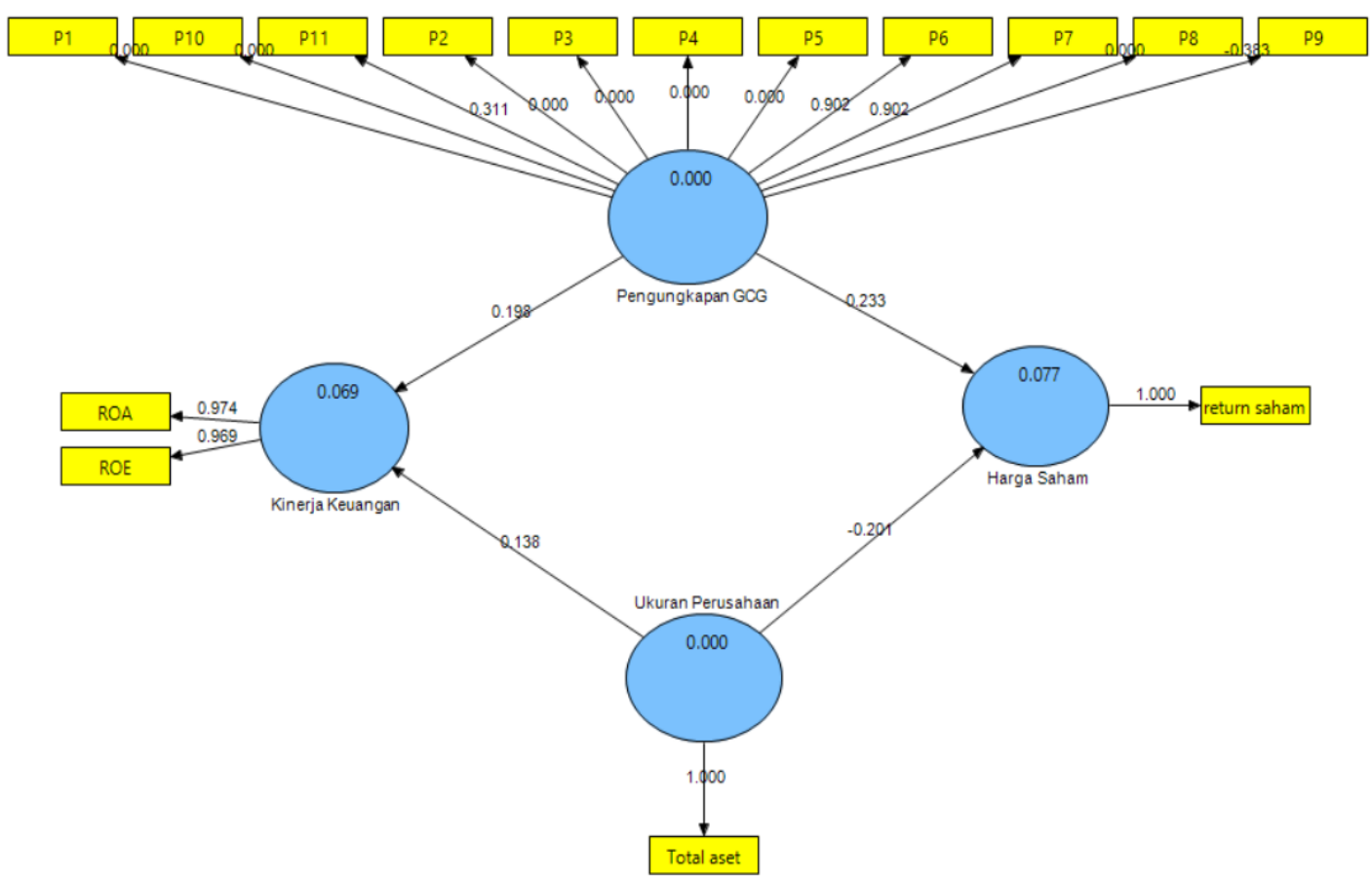

Gambar 1. Model awal untuk penghitungan Algoritma PLS

Sumber: Hasil olahan SmartPLS 2.0

Kemudian dilakukan eksekusi berulang sehingga diperoleh nilai akhir loading $\geq$ 0,40 untuk masing-masing indikator dan diperoleh hasil akhir sebagai berikut:

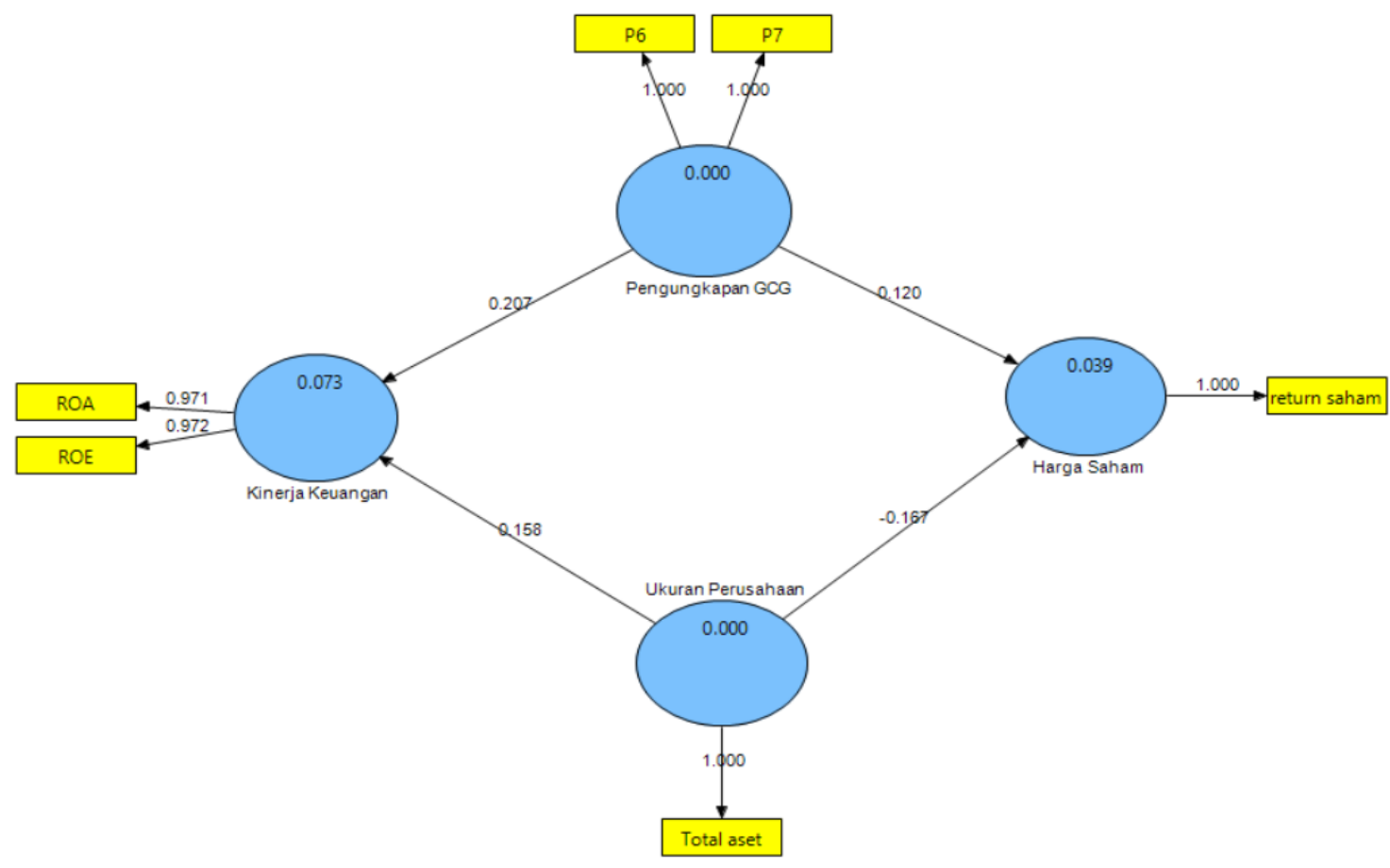

Gambar 2. Hasil penghitungan akhir Algoritma PLS

Sumber: Hasil olahan SmartPLS 2.0 
Terlihat indikator/variabel yang dibuang adalah Pemegang saham (P1), Dewan komisaris (P2), Direksi (P3), Auditor eksternal (P4), Informasi (P5), Hubungan dengan Pemangku kepentingan (P8), Etika berusaha, anti korupsi dan donasi (P9), Program pengenalan BUMN (P10), dan Pengukuran terhadap penerapan GCG (P11), sehingga model sudah dapat dikatakan stabil. Hasil pengukuran dengan menggunakan smartPLS, dapat dilihat pada Tabel 2.

Tabel 2. Penghitungan Akhir Algoritma PLS

\begin{tabular}{clcc}
\hline No & \multicolumn{1}{c}{ Konstruk } & Nilai kekuatan Interelasi & Indikator \\
\hline \multirow{2}{*}{1} & Pengungkapan & 1,00 & Keselamatan dan kesempatan kerja (P6) \\
& Penerapan GCG & 1,00 & Pelestarian lingkungan (P7) \\
2 & Kinerja keuangan & 0,971 & ROA \\
3 & Ukuran Perusahaan & 0,972 & TA \\
4 & Harga saham & 1,00 & ARS \\
\hline
\end{tabular}

Sumber: Hasil olahan SmartPLS 2.0

\section{Discriminant Validity}

Discriminant validity digunakan untuk memastikan bahwa setiap konsep dari variabel laten/konstruk berbeda dengan variabel laten lainnya. Model mempunyai discriminant validity yang baik jika setiap nilai loading dari setiap indikator dari sebuah variabel laten memiliki nilai loading yang paling besar dengan nilai loading lain terhadap variabel latennya. Hasil pengujian discriminant variability dapat dilihat pada Tabel 3.

Tabel 3. Penghitungan nilai cross loading indikator

\begin{tabular}{lcccc}
\hline & $\begin{array}{c}\text { Pengungkapan } \\
\text { GCG }\end{array}$ & Kinerja Keuangan & Ukuran Perusahaan & Return Saham \\
\hline P6 & 1,0000 & 0,2191 & 0,0783 & 0,1074 \\
P7 & 1,0000 & 0,2191 & 0,0783 & 0,1074 \\
ROA & 0,1860 & 0,9713 & 0,2019 & $-0,4440$ \\
ROE & 0,2394 & 0,9718 & 0,1362 & $-0,2674$ \\
Total aset & 0,0783 & 0,1739 & 1,0000 & $-0,1575$ \\
Return saham & 0,1074 & $-0,3657$ & $-0,1575$ & 1,0000 \\
\hline
\end{tabular}

Sumber: Hasil Olahan SmartPLS 2.0

Berdasarkan Tabel 3, dapat terlihat bahwa nilai korelasi dari indikator terhadap konstruk lebih besar dibandingkan dengan korelasi indikator tersebut dengan konstruk lain. Hal ini menunjukkan bahwa model pada konstruk di penelitian ini dinyatakan valid.

\section{Composite Reliability}

Kriteria validitas dan reliabilitas juga dapat dilihat dari nilai reliabilitas suatu indikator dari masing-masing variabel laten. Indikator dari variabel laten dikatakan memiliki reliabilitas tinggi jika nilainya 0,70. Hasilnya seperti terlihat pada Tabel 4. 
Tabel 4. Composite Realibility

\begin{tabular}{lc}
\hline & Composite Reliability \\
\hline Penerapan GCG & 1,0000 \\
Kinerja Keuangan & 0,9712 \\
Ukuran Perusahaan & 1,0000 \\
Harga Saham & 1,0000 \\
\hline
\end{tabular}

Sumber: Hasil Olahan SmartPLS 2.0

Berdasarkan Tabel 4 menunjukkan semua variabel adalah reliabel karena nilai compisite reliability diatas 0,70 sebagaimana kriteria yang direkomendasikan.

\section{III.2. Pengujian Inner Model (Model Struktural)}

Pengujian inner model dilakukan untuk melihat nilai signifikasi masing-masing indikator dengan uji $t$, signifikasi hubungan antara variable laten dengan uji t sesuai parameter jalur strukturalnya dan nilai R-square dari model penelitian. Pengujian tersebut dilakukan melalui SmartPLS 2,0 dengan melakukan langkah calculatebootstrapping dan diperoleh hasil sebagai berikut :

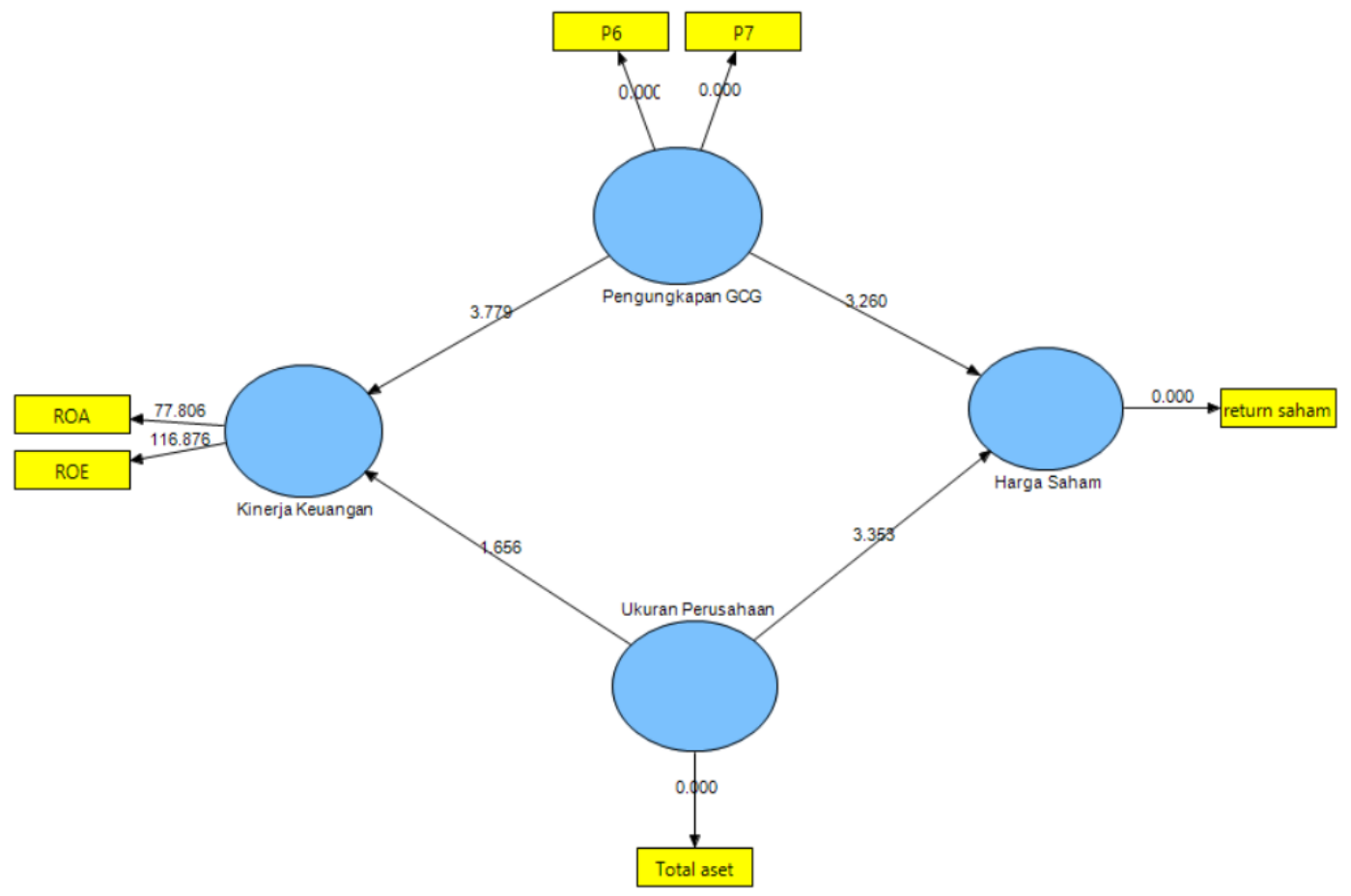

Gambar 3. Hasil Bootstrapping

Sumber: Hasil Olahan SmartPLS 2.0

Penilaian dan pengujian hasil dari perhitungan bootstrapping pada SmartPLS 2.0 adalah :

\section{Nilai Signifikasi Masing-masing Indikator}

Diperoleh dari hasil perhitungan t-statistik pada masing-masing indikator pada kelompok masing-masing variabel latennya dengan ketentuan dianggap indikator tersebut signifikan jika nilai t-statistiknya $>1,96$ (pada alfa 5\%). Berdasarkan hasil olahan data, menunjukkan indikator-indikator yang memiliki nilai t-statistiknya $>1,96$, yaitu Pengungkapan Penerapan GCG terhadap Kinerja Keuangan dan Harga Saham dan 
indikator Ukuran Perusahaan terhadap Harga saham, yang berarti bahwa indikator tersebut mempunyai nilai yang signifikan. Sedangkan Ukuran Perusahaan terhadap Kinerja Keuangan memiliki nilai t-statistiknya $<1,96$, yang berarti bahwa indikator tersebut tidak mempunyai nilai yang signifikan.

\section{Nilai Signifikansi Hubungan Antar Variabel Laten}

Uji untuk melihat signifikansi antar indikator variabel laten dapat dinilai dengan melihat angka koefisien dan nilai signifikansi t-statistik pada Tabel 5.

Tabel 5. Path coefficients

\begin{tabular}{lccccc}
\hline & $\begin{array}{c}\text { Original } \\
\text { Sample (O) }\end{array}$ & $\begin{array}{c}\text { Sample } \\
\text { Mean (M) }\end{array}$ & $\begin{array}{c}\text { Standard } \\
\text { Deviation } \\
\text { (STDEV) }\end{array}$ & $\begin{array}{c}\text { Standard Error } \\
\text { (STERR) }\end{array}$ & $\begin{array}{c}\text { t Statistics } \\
\text { (|O/STERR|) }\end{array}$ \\
\hline $\begin{array}{l}\text { Pengungkapan } \\
\text { penerapan GCG -> }\end{array}$ & 0,1205 & 0,1195 & 0,0318 & 0,0318 & 3,7933 \\
$\begin{array}{l}\text { Harga Saham } \\
\text { Pengungkapan }\end{array}$ & 0,2067 & 0,2100 & 0,0483 & 0,0483 & 4,2778 \\
$\begin{array}{l}\text { penerapan GCG -> } \\
\text { Kinerja Keuangan } \\
\text { Ukuran Perusahaan }\end{array}$ & $-0,1669$ & $-0,1744$ & 0,0621 & 0,0621 & 2,6887 \\
$->$ Harga Saham \\
$\begin{array}{l}\text { Ukuran Perusahaan } \\
->\text { Kinerja Keuangan }\end{array}$ & 0,1577 & 0,1491 & 0,1123 & 0,1123 & 1,4047 \\
\hline
\end{tabular}

Sumber: Hasil Olahan SmartPLS 2.0

\section{R-square}

Pengujian terhadap inner model dilakukan dengan melihat nilai $R$-square yang merupakan uji goodness-fit model. Hasil dari $R$-square terangkum pada Tabel 6.

Tabel 6. R-square

\begin{tabular}{lc}
\hline & R Square \\
\hline Pengungkapan penerapan GCG & 0,0000 \\
Kinerja Keuangan & 0,0727 \\
Ukuran Perusahaan & 0,0000 \\
Harga saham & 0,0392 \\
\hline
\end{tabular}

Sumber: Hasil Olahan SmartPLS 2.0

Tabel 6 menunjukkan nilai $R$-square untuk variabel laten kinerja keuangan didapatkan nilai sebesar 0,0727, hal ini menunjukkan bahwa variabel laten pengungkapan penerapan GCG dan ukuran perusahaan berhubungan sebesar $7,27 \%$ terhadap kinerja keuangan. Sedangkan sisanya dijelaskan oleh variabel lain yang tidak termasuk dalam penelitian ini. Nilai $R$-square yang rendah diduga terjadi karena faktor yang mendorong perusahaan untuk mengungkapkan penerapan GCG adalah masih sekedar trend. Perusahaan melakukan pengungkapan informasi dan penerapan GCG sekedar mematuhi peraturan atau karena tekanan pelaku pasar khususnya pelaku pasar internasional. Hasil penelitian ini sejalan dengan hasil penelitian yang dilakukan oleh Prasinta (2012).

Sementara nilai $R$-square untuk variabel harga saham didapatkan nilai sebesar 0,0392 , hal ini menunjukkan bahwa variabel laten pengungkapan penerapan GCG dan 
ukuran perusahaan berhubungan sebesar 3,92\% terhadap harga saham. Sedangkan sisanya dijelaskan oleh variabel lain yang tidak termasuk dalam penelitian ini. Nilai $R$ square yang rendah dikarenakan harga saham memang tidak hanya dipengaruhi oleh pengungkapan penerapan GCG dan ukuran perusahaan. Harga saham lebih banyak dipengaruhi oleh rasio-rasio fundamental perusahaan itu sendiri.

\section{Kesimpulan}

Kesimpulan yang dapat diambil dalam penelitian ini adalah pengungkapan penerapan GCG didalam laporan tahunan berhubungan signifikan terhadap harga saham. Hal ini berarti semakin tinggi pengungkapan GCG semakin baik harga saham perusahaan. Pengungkapan penerapan GCG berhubungan signifikan terhadap kinerja keuangan. Hal ini berarti semakin tinggi pengungkapan GCG semakin baik kinerja keuangan perusahaan. Ukuran perusahaan berhubungan signifikan terhadap harga saham. Hal ini berarti stakeholder mulai mempertimbangkan ukuran perusahaan dalam berinvestasi. Ukuran perusahaan tidak berhubungan signifikan terhadap kinerja keuangan. Hal ini berarti ukuran perusahaan tidak mempengaruhi kinerja keuangan suatu perusahaan.

Saran yang dapat kami berikan dalam penelitian ini adalah agar perusahaan menerapkan GCG tersebut sesuai dengan tujuan dikeluarkannya yaitu agar terciptanya perusahaan yang sehat dan bersih. Bagi pemilik modal, diharapkan ikut berpartisipasi dalam penerapan GCG dengan melakukan monitoring atas pelaporan keuangan guna menjadi sumber informasi bagi perusahaan sehingga mekanisme GCG bisa lebih optimal dan terkontrol. Penelitian ini terbatas hanya pada perusahan BUMN dan yang terdaftar pada Bursa Efek Indonesia.

\section{Daftar Pustaka}

Jogiyanto HM. 2003. Teori Portofolio dan Analisis Investasi Edisi Ketiga. Yogyakarta (ID): BPFE UGM.

Kasmir. 2011. Analisis Laporan Keuangan. Jakarta (ID): Rajawali Pers.

Lastanti HS. 2004. Hubungan Struktur Corporate governance dengan Kinerja Perusahaan dan Reaksi Pasar. Konferensi Nasional Akutansi, Peran Akuntan dalam Membangun Good Corporate governance sesi Akutansi Manajement.

Peraturan Menteri Negara Badan Usaha Milik Negara Nomor: Per-01/MBU/2011 tentang Penerapan Tata Kelola Perusahaan yang Baik (Good Coperate Governance) pada Badan Usaha Milik Negara.

Prasinta D. 2012. Pengaruh Good Coperate Governance Terhadap Kinerja Keuangan. Accounting Analysis Journal. 1 (2): 1-7.

Undang-undang No.19 tahun 2003 tentang Badan Usaha Milik Negara (BUMN).

Yamin S, Kurniawan H. 2009. Structural Equation Modeling (belajar lebih mudah teknik analisis data kuesioner dengan Lisrel - PLS). Jakarta (ID): Salemba Infotek.

. 2011. Generasi Baru Mengolah Data dengan Partial Least Square Path Modeling. Jakarta (ID): Salemba Infotek. 